\title{
EDITORIAL
}

\section{Pulmonary infiltrates in patients with malignancies: why and how neutropenia influences clinical reasoning}

\author{
É. Azoulay*\#
}

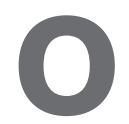
ver the last two decades, increased intensity of anticancer therapy in patients with solid tumours or haematological malignancies has translated into better survival [1]. Overall, more patients are being treated, the treatments they receive are more aggressive, and patients more often undergo stem cell transplantation [2]. The result is an increase in the number of cases of patients with neutropenia [3].

Neutropenia is a decrease in circulating neutrophil counts in the peripheral blood. An absolute neutrophil count of 1,0001,500 cells $\cdot \mathrm{mm}^{-3}$ defines mild neutropenia, $500-1,000$ cells $\cdot \mathrm{mm}^{-3}$ defines moderate neutropenia, and $<500$ cells $\cdot \mathrm{mm}^{-3}$ defines severe neutropenia. In patients with pneumonia or acute respiratory failure, neutropenia may influence the clinical reasoning in three different ways.

First, although neutrophils are believed to be pivotal in the pathophysiology of acute respiratory distress syndrome and acute lung injury, these conditions can occur in neutropenic patients, as shown by the clinical and experimental literature [4-6]. In addition, respiratory deterioration during neutropenia is probably due to complex interactions between resident macrophages and migrated neutrophils sequestered in the lung interstitium, with upregulation of pro-inflammatory cytokines such as tumour necrosis factor- $\alpha$ and interleukin-1 $\beta$ $[7,8]$. Exogenous granulocyte colony-stimulating factor may promote respiratory deterioration during neutropenia recovery $[7,9]$. Macrophage deactivation may occur during granulocyte colony-stimulating factor therapy [10, 11], and granulocyte colony-stimulating factor may play a role in the upregulation of anti-inflammatory mediators, despite its ability to exacerbate lung injury [12].

Second, the type of immune dysfunction is one of the main clues to the cause of lung infiltrates [13]. In a recent cohort of 326 adult patients undergoing autologous stem cell transplantation, the risk of pneumonia was higher in patients who had

*Assistance-Publique Hôpitaux de Paris, Hôpital Saint-Louis, Medical ICU, and \#University Paris-7 Paris-Diderot, UFR de Médecine, Paris, France.

SUPPORT STATEMENT: Supported, in part, by grant AOM 04139 from the Assistance-Publique Hôpitaux de Paris (Hôpital Saint-Louis, Medical ICU, Paris, France), and by a research grant from the French Society for Critical Care Medicine (Paris).

STATEMENT OF INTEREST: A statement of interest for É. Azoulay can be found at www.erj.ersjournals.com/misc/statements.shtml

CORRESPONDENCE: É. Azoulay, Hôpital Saint-Louis, 1 avenue Claude Vellefaux, 75010 Paris, France. Fax: 33 142499426. E-mail: elie.azoulay@sls.ap-hop-paris.fr myeloma or severe neutropenia for $>7$ days [14]. In addition, pneumonia is associated with an increased risk for septic shock and mortality [15]. In allogeneic stem cell transplantation, pulmonary complications are the events associated with the highest fatality rates, and pneumonia risk is highest after unrelated donor allogeneic peripheral blood stem cell transplantation [16]. Bacterial infections account for most cases of lung involvement in neutropenic patients [17]. The risk of bacterial infection is related to both the severity and the duration of the neutropenia [18]. Because laboratory techniques lack sensitivity in these patients, who routinely receive empirical antibiotics, the diagnosis usually relies on clinical data only [19]. Fungal infections should be considered only in patients with severe or prolonged neutropenia, immunosuppressive therapy to control graft versus host disease and, perhaps, those receiving targeted therapy such as rituximab [20].

Third, the prognostic significance of neutropenia itself has been controversial for years. In this issue of the European Respiratory Journal, ALIBERTI et al. [21] compare clinical outcomes of cancer patients admitted for community-acquired pneumonia with $(n=73)$ or without $(n=135)$ neutropenia. Overall, community-acquired pneumonia patients with cancer were found to have higher mortality rates than communityacquired pneumonia patients without cancer. However, among cancer patients, neutropenia did not influence time to clinical stability, length of hospital stay or in-hospital mortality. The study by AliBERTI et al. [21] is in agreement with most of the studies reported over the last decade, in which neutropenia has supplied no prognostic information in cancer patients with acute respiratory failure [22, 23], even those requiring mechanical ventilation [24, 25]. However, neutropenia has been associated with outcomes in studies focusing on the overall population of critically ill cancer patients [26-28]. Several factors may explain why neutropenia is no longer associated with death in cancer patients admitted to the intensive care unit for acute respiratory failure. 1) As early studies discouraged the use of life-supporting treatments in patients with acute respiratory failure and malignancies [29, 30], neutropenic patients were perhaps less often referred to emergency departments. Therefore, neutropenic patients selected for inclusion in the Community-Acquired Pneumonia Organization database may not represent the actual picture of all neutropenic patients with community-acquired pneumonia. However, major advances in both cancer and intensive care unit management make these early studies obsolete [31]. 2) No information is available regarding the duration of neutropenia or the timing of neutropenia recovery. The results of ALIBERTI 
et al. [21] come chiefly from patients with solid tumours, which are usually associated with far shorter chemotherapy-induced neutropenia duration ( $<5-7$ days $)$ than haematological malignancies. Different results would perhaps have been obtained in patients with refractory neutropenia or in recipients of allogeneic stem cell transplants [32, 33]. Therefore, the prognostic information may lie not in the presence of neutropenia but in the type of underlying malignancy and treatment. 3) The chemotherapy response (e.g. remission) has not been reported. Patients receiving potentially curative chemotherapy are less likely to have treatment-limitation decisions than patients receiving palliative chemotherapy. Thus, although neutropenia develops in both groups, the use of life-supporting treatments may differ. It is of the utmost importance to offer full-code management, including lifesupporting interventions, to patients at the earliest phase of their malignancy and to those receiving potentially lifespanextending treatments [34]. In patients under palliative care, the management of life-threatening complications during neutropenia should strike the optimal balance between benefits from interventions and risks of severe quality-of-life alterations. In this situation, the decision to use life-supporting treatments should be based on the patient's preferences and values [35].

\section{REFERENCES}

1 Brenner H, Gondos A, Arndt V. Recent major progress in long-term cancer patient survival disclosed by modeled period analysis. J Clin Oncol 2007; 25: 3274-3280.

2 Khassawneh BY, White P Jr, Anaissie EJ, Barlogie B, Hiller FC. Outcome from mechanical ventilation after autologous peripheral blood stem cell transplantation. Chest 2002; 121: 185-188.

3 Cullen M, Steven N, Billingham L, et al. Antibacterial prophylaxis after chemotherapy for solid tumors and lymphomas. N Engl J Med 2005; 353: 988-998.

4 Ognibene FP, Martin SE, Parker MM, et al. Adult respiratory distress syndrome in patients with severe neutropenia. N Engl J Med 1986; 315: 547-551.

5 Azoulay E, Attalah H, Yang K, et al. Exacerbation by granulocyte colony-stimulating factor of prior acute lung injury: implication of neutrophils. Crit Care Med 2002; 30: 2115-2122.

6 Braude S, Apperley J, Krausz T, Goldman JM, Royston D. Adult respiratory distress syndrome after allogeneic bonemarrow transplantation: evidence for a neutrophilindependent mechanism. Lancet 1985; 1: 1239-1242.

7 Azoulay E, Attalah H, Yang K, et al. Exacerbation with granulocyte colony-stimulating factor of prior acute lung injury during neutropenia recovery in rats. Crit Care Med 2003; 31: 157-165.

8 Azoulay E, Darmon M, Delclaux C, et al. Deterioration of previous acute lung injury during neutropenia recovery. Crit Care Med 2002; 30: 781-786.

9 Karlin L, Darmon M, Thiery G, et al. Respiratory status deterioration during G-CSF-induced neutropenia recovery. Bone Marrow Transplant 2005; 6: 6.

10 Mokart D, Guery BP, Bouabdallah R, et al. Deactivation of alveolar macrophages in septic neutropenic ARDS. Chest 2003; 124: 644-652.
11 Mokart D, Kipnis E, Guerre-Berthelot P, et al. Monocyte deactivation in neutropenic acute respiratory distress syndrome patients treated with granulocyte colony-stimulating factor. Crit Care 2008; 12: R17.

12 Wiedermann FJ, Mayr AJ, Hobisch-Hagen P, Fuchs D, Schobersberger W. Association of endogenous G-CSF with anti-inflammatory mediators in patients with acute respiratory distress syndrome. I Interferon Cytokine Res 2003; 23: 729-736.

13 Azoulay E, Schlemmer B. Diagnostic strategy in cancer patients with acute respiratory failure. Intensive Care Med 2006; 32: 808-822.

14 Puig N, De La Rubia J, Jarque I, et al. Characteristics of and risk factors for pneumonia in patients with hematological malignancies developing fever after autologous blood stem cell transplantation. Leuk Lymphoma 2007; 48: 2367-2374.

15 Ramzi J, Mohamed Z, Yosr B, et al. Predictive factors of septic shock and mortality in neutropenic patients. Hematology 2007; 12: 543-548.

16 Meyer E, Beyersmann J, Bertz H, et al. Risk factor analysis of blood stream infection and pneumonia in neutropenic patients after peripheral blood stem-cell transplantation. Bone Marrow Transplant 2007; 39: 173-178.

17 Gruson D, Hilbert G, Portel L, et al. Severe respiratory failure requiring ICU admission in bone marrow transplant recipients. Eur Respir J 1999; 13: 883-887.

18 Bodey GP, Buckley M, Sathe YS, Freireich EJ. Quantitative relationships between circulating leukocytes and infection in patients with acute leukemia. Ann Intern Med 1966; 64: 328-340.

19 Cordonnier C, Escudier E, Verra F, Brochard L, Bernaudin JF, Fleury-Feith J. Bronchoalveolar lavage during neutropenic episodes: diagnostic yield and cellular pattern. Eur Respir J 1994; 7: 114-120.

20 Gil L, Kozlowska-Skrzypczak M, Mol A, Poplawski D, Styczynski J, Komarnicki M. Increased risk for invasive aspergillosis in patients with lymphoproliferative diseases after autologous hematopoietic SCT. Bone Marrow Transplant 2008; 15: 15.

21 Aliberti S, Myers JA, Peyrani P, et al. The role of neutropenia on outcomes of cancer patients with community-acquired pneumonia. Eur Respir J 2009; 33: 142-147.

22 Azoulay E, Mokart D, Rabbat A, et al. Diagnostic bronchoscopy in hematology and oncology patients with acute respiratory failure: prospective multicenter data. Crit Care Med 2008; 36: 100-107.

23 Azoulay E, Thiery G, Chevret S, et al. The prognosis of acute respiratory failure in critically ill cancer patients. Medicine (Baltimore) 2004; 83: 360-370.

24 Azoulay E, Alberti C, Bornstain C, et al. Improved survival in cancer patients requiring mechanical ventilatory support: impact of noninvasive mechanical ventilatory support. Crit Care Med 2001; 29: 519-525.

25 Soares M, Salluh JI, Spector N, Rocco JR. Characteristics and outcomes of cancer patients requiring mechanical ventilatory support for $>24$ hrs. Crit Care Med 2005; 33: 520-526.

26 Benoit DD, Vandewoude KH, Decruyenaere JM, Hoste EA, Colardyn FA. Outcome and early prognostic indicators in patients with a hematologic malignancy admitted to the 
intensive care unit for a life-threatening complication. Crit Care Med 2003; 31: 104-112.

27 Sculier JP, Paesmans M, Markiewicz E, Berghmans T. Scoring systems in cancer patients admitted for an acute complication in a medical intensive care unit. Crit Care Med 2000; 28: 2786-2792.

28 Blot F, Guiguet M, Nitenberg G, Leclercq B, Gachot B, Escudier B. Prognostic factors for neutropenic patients in an intensive care unit: respective roles of underlying malignancies and acute organ failures. Eur J Cancer 1997; 33: 1031-1037.

29 Ewig S, Torres A, Riquelme R, et al. Pulmonary complications in patients with haematological malignancies treated at a respiratory ICU. Eur Respir J 1998; 12: 116-122.

30 Snow RM, Miller WC, Rice DL, Ali MK. Respiratory failure in cancer patients. JAMA 1979; 241: 2039-2042.
31 Groeger JS, Bach PB. Consider saying yes. Crit Care Med 2003; 31: 320-321.

32 Darmon M, Azoulay E, Alberti C, et al. Impact of neutropenia duration on short-term mortality in neutropenic critically ill cancer patients. Intensive Care Med 2002; 28: 1775-1780.

33 Pene F, Aubron C, Azoulay E, et al. Outcome of critically ill allogeneic hematopoietic stem-cell transplantation recipients: a reappraisal of indications for organ failure supports. J Clin Oncol 2006; 24: 643-649.

34 Azoulay E, Afessa B. The intensive care support of patients with malignancy: do everything that can be done. Intensive Care Med 2006; 32: 3-5.

35 Fried TR, Bradley EH, Towle VR, Allore H. Understanding the treatment preferences of seriously ill patients. $N$ Engl J Med 2002; 346: 1061-1066. 